\title{
Late nitrogen application enhances spikelet number in indica hybrid rice (Oryza
}

\section{sativa L.)}

Wei Zhou, Tengfei Lv, Yong Chen, Jianfeng Hu, Qiang Zhang, Wanjun Ren*

Sichuan Agricultural University - Chengdu - 611130 Sichuan - China.

*Corresponding author <rwjun@126.com>

Edited by: Axel Garcia y Garcia

Received March 11, 2016

Accepted May 11, 2016

\begin{abstract}
To increase rice yield potential, field experiments were conducted in farmers' paddies in 2011 and 2012 to evaluate the effects of different nitrogen applications on the yield and panicle components of three typical indica hybrid rice varieties in Sichuan Province. The number of grains per panicle resulting from late nitrogen application (LA) was $12 \%$ greater than that obtained from traditional nitrogen application (TA); this increase was the main source of improvements in yield. The number of surviving and differentiated spikelets (NSS and NDiS) resulting from LA was significantly higher than that measured under TA, especially for the Fyou498 cultivar, where the NSS and NDiS increased by $15 \%$ and $14 \%$, respectively. Compared with TA, the number of degenerated secondary branches and the percentage of degenerated secondary branches (NDeSB and PDeSB) were significantly reduced by $9 \%$ and $11 \%$, respectively, by LA. This is the first study to demonstrate that an increase in NSS and a decrease in NDeSB lead to yield-improving effects attributable to $L A$. The grain yields of different varieties ranged from 9225.6 to $9408.7 \mathrm{~kg} \mathrm{ha}^{-1}$, the PDeSB was as high as $31 \%$, and the number of surviving secondary branches (NSSB) was significantly and positively correlated with NSS. These data indicate that the yield of indica hybrid rice has considerable potential for being improved, and increasing NSSB is key to increasing NSS and improving the grain yield. These improvements should be pursued so as to increase the yield of hybrid rice to ensure both food security and sustainable agricultural development.

Keywords: panicle, grain number, branch, degenerated rate, yield
\end{abstract}

\section{Introduction}

The Green Revolution has greatly enhanced crop yield and has been successfully resolving the global food crisis since the 1960s (Wang and Li, 2011); however, the pressure on soil and other resources has intensified (Bueno and Ladha, 2009). The area under cultivation is continually contracting as a result of soil pollution, land abandonment, urbanization, amongst other reasons (Gathala et al., 2011). Meanwhile, rapid population growth and economic development continue to exert growing pressure on the need to increase food production (Zhang, 2007). This being the situation, increasing the rice yield per hectare of land is the key to guaranteeing food security given the current amount of available agricultural land.

The average rice yield of Sichuan Province from 2006 to 2013 was $6589 \mathrm{~kg} \mathrm{ha}^{-1}$ (http://www.sc.stats.gov. cn/tjcbw/tjnj/2014/index.htm). Rice grain yield is determined by many factors, of which the NSS is the key factor. As pre-flowering spikelet abortion occurs often (Kato et al., 2008), the NSS per unit area is primarily determined by NDiS and secondarily, by the number of degenerated spikelets (NDeS) (Kamiji et al., 2011). Research studies have shown that NSS and NDiS per panicle are positively related to dry weight (Shiratsuchi, et al., 2007; Yao, 2000), leaf area per tiller (Sheehy et al., 2001), neck internode diameter (Liu et al., 2008a), and the amount of nitrogen accumulated up to the late spikelet differentiation stage (Matsui and Kagata, 2002;
Shiratsuchi et al., 2007). Nitrogen is one of the key nutrients that limit crop growth and the yield potential of cereals in many production systems. Nitrogen fertilizer applied at the panicle initiation stage has become a commonly used strategy to enhance panicle weight in China in recent years. Although our understanding of panicle growth and development is very clear, the mechanism underlying the influence of nitrogen applied at the panicle initiation stage is still unknown, especially for the heavy-panicle rice varieties.

Because of the irreplaceable role of indica hybrid rice and the key role of spikelet number in rice yield (Liu et al., 2008b), we chose three main popularized cultivars of Sichuan Province to (i) study the influencing mechanism of nitrogen applied at the panicle initiation stage on the differentiation and degradation of branches and spikelets and (ii) evaluate the potential yield increase of indica hybrid rice. This study provides information for developing and refining nitrogen management in irrigated paddy fields and may thus make a meaningful contribution to increasing the yield of indica hybrid rice.

\section{Materials and Methods}

\section{Experimental site and ethics statement}

The experiment was conducted in paddy fields in Gucheng Town of Chengdu City, Sichuan Province, China (lat. $30^{\circ} 93^{\prime} \mathrm{N}$, long. $103^{\circ} 91^{\prime} \mathrm{E}, 548-\mathrm{m}$ elevation), during the rice growing seasons of 2011 and 2012. The region is classified as humid sub-tropical with a monsoon 
climate. The experiments were carried out on fluviate, sandy loam soil, and the characteristics of the soil are described in Table 1. These field studies did not involve any endangered or protected species; no specific permits were required for the described field studies, and the landowner (Rice Super-high-yield Production Model Base) permitted these field studies to be carried out.

\section{Experimental design}

The experiments were laid out in a two-factor randomized block design with three indica hybrid rice varieties and two nitrogen treatments, and were replicated three times. The test materials were Fyou498 (F32A $\times$ Shuhui498), IIyou498 (II-32A $\times$ Shuhui498), and Chuanxiang9838 (Chuangxiang29A $\times$ Fuhui838) cultivars. The two nitrogen applications contained the same total nitrogen rate of $180 \mathrm{~kg} \mathrm{ha}^{-1}$. The TA treatment consisted of $70 \%$ applied as a basal fertilizer and $30 \%$ applied at early tillering; the LA treatment consisted of $35 \%$ applied as a basal fertilizer, $15 \%$ applied at the early tillering stage, and $50 \%$ at the panicle initiation stage. The plot area was $30 \mathrm{~m}^{2} ; 20-\mathrm{cm}$-high ridges were built between the plots and coated with a film to prevent the fertilizer and water from moving to the adjacent plots. Fertilizer used as a basal dressing was applied at the following rates: $90 \mathrm{~kg} \mathrm{P}_{2} \mathrm{O}_{5} \mathrm{ha}^{-1}$ (applied as superphosphate), $90 \mathrm{~kg} \mathrm{~K}_{2} \mathrm{O} \mathrm{ha}^{-1}$ (applied as $\mathrm{KCl}$ ), and nitrogen (ammonium bicarbonate) were applied in accordance with the different treatments. Additional nitrogen (applied as ammonium bicarbonate) was broadcast at the tillering stage, and $90 \mathrm{~kg} \mathrm{~K}_{2} \mathrm{O} \mathrm{ha}^{-1}$ (applied as $\mathrm{KCl}$ ) and nitrogen topdressing (applied as urea) were broadcast at the panicle initiation stage. In 2011, the seeds were sown on 30 Mar, transplanted into the plots on 30 May, and harvested on 10 Sept. In 2012, the seeds were sown on 28 Mar, transplanted into the plots on 28 May, and harvested on 11 Sept. The transplanting density was 20 $\mathrm{cm} \times 33 \mathrm{~cm}$. The irrigation water was maintained at a depth of $1-5 \mathrm{~cm}$ for one week following transplantation to aid seedling establishment. Pests were controlled according to the standard recommendation, and other rice management practices were similar to those in the paddy field.

\section{Indexes and measurement methods}

\section{Determination of yield and its components}

Rice was harvested at the maturing stage in 2011 and 2012, and the yield of each plot was recorded. After measurement of the moisture content and removal of

Table 1 - Soil characteristics of the experiments.

\begin{tabular}{|c|c|c|c|c|c|}
\hline Year & $\begin{array}{l}\text { Organic } \\
\text { matter }\end{array}$ & Total N & $\begin{array}{l}\text { Alkali hydrolysable } \\
\text { N }\end{array}$ & Olsen-P & $\underset{\mathrm{K}}{\text { Exchangeable }}$ \\
\hline & \multicolumn{2}{|c|}{$-\mathrm{g} \mathrm{kg}^{-1} \longrightarrow$} & \multicolumn{3}{|c|}{$\mathrm{mg} \mathrm{kg}^{-1}$} \\
\hline 2011 & 32.14 & 1.61 & 102.68 & 51.47 & 99.26 \\
\hline 2012 & 30.70 & 1.53 & 117.36 & 41.40 & 52.73 \\
\hline
\end{tabular}

impurities, the standard grain output of each plot was determined at a moisture content of $14 \%$. Before harvest, the number of effective panicles per hill was determined from 60 hills per plot, and then 5 hills per plot that contained the average number of effective panicles were taken to the laboratory to examine the 1000-grain weight, seed setting percentage and number of grains per panicle.

\section{Structure and components of panicles}

Based on the results of the experiment in 2011, we focused on the effects of LA on the panicle characteristics in 2012. In each plot, 30 stems that had eared consistently were randomly marked at the first heading stage, and 10 marked stems without any diseases or insect pests were investigated at the full heading stage to determine the number of surviving and degenerated primary branches (NSPB and NDePB), NSS, NDeS, NSSB, and NDeSB. The degenerated sites were recorded at the same time; these were marked from the base to the top of the panicle (Figure 1). Then, the percentages of degenerated primary branches (PDePB), the percentages of degenerated spikelets (PDeS) and PDeSB were calculated as follows: differentiated number $=$ surviving number + degenerated number; percentage of degenerated $=$ degenerated number / differentiated number $\times 100 \%$.

\section{Data analysis}

The experiment was performed as a two-factor experiment with a completely randomized design replicated three times. The data were subjected to analysis of variance, a comparison of treatments and varieties, and a mapping analysis. String diagrams were used to assess the differences between and tendencies among the mean values of the different attributes, and the comparisons were conducted using an LSD multiple-range test at 0.05 and 0.01 probability levels.

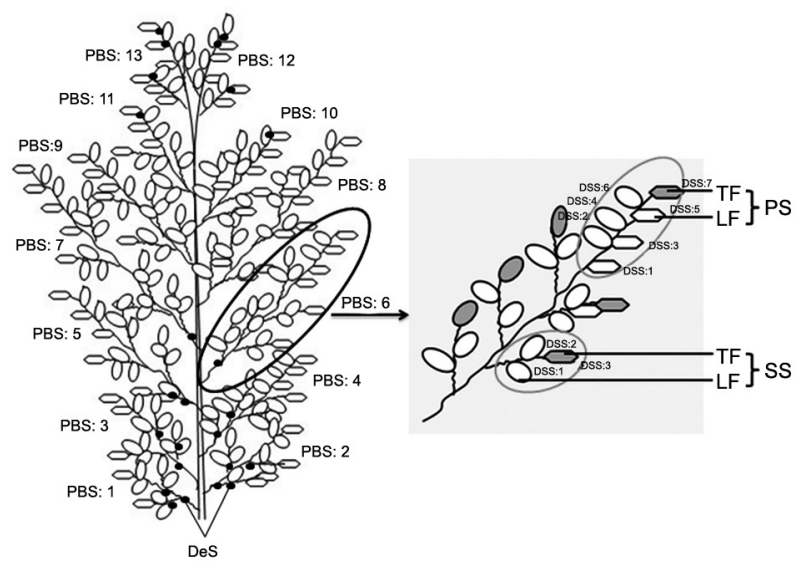

Figure 1 - Structure and components of panicles. DSS = degradation site of spikelet; LF = lateral floret; PBS = primary branch site; PS = primary spikelet; DeS = degenerated site; SS = secondary spikelet; TF $=$ terminal floret. 


\section{Results and Discussion}

Yield-increasing effect of late nitrogen application The yield components, including the number of panicles, grains and setting percentage, were significantly affected by cultivar, which indicates that the 1000grain weight is a relatively stable component in indica hybrid rice varieties (Table 2). The average grain yield (LA and TA management treatments) of the different varieties ranged from 9225.6 to $9408.7 \mathrm{~kg} \mathrm{ha}^{-1}$, and the differences were not significant. There was a compensating effect among the different yield components: cultivar Fyou 498 had the highest number of grains per panicle, cultivar Chuanxiang9839 had the highest number of panicles, and cultivar IIyou498 had the highest setting percentage and 1000-grain weight.

The difference in the number of panicles between TA and LA was not significant. This similarity indicated that reducing the base fertilizer appropriately would not decrease the number of panicles at harvest. Nitrogen treatment had a significant effect on grain yield; LA increased yield by approximately $6 \%$ compared with TA. This increase in yield resulted mainly from the change in grain number. The number of grains per panicle resulting from LA was $12 \%$ higher than that of TA. This percentage increase is equivalent to more than 19 grains per panicle. Studies have shown that nitrogen limits grain yield through its effect on plant biomass and, consequently, grain number and size in cereals (Angus et al., 1993; Demotes and Jeuffroy, 2001). Nitrogen topdressing, especially at the neck node initiation stage, could effectively increase the number of spikelets per unit area (Ding and Maruyama, 2004). The present study demonstrated that even for Chinese indica hybrid rice, which is a large-panicle cultivar that contains more spikelets than many other rice cultivars, LA can still increase the number of grains and therefore improve yield. Qin et al. (2013) provided evidence that a larger sink does not necessarily result in poor grain filling when sufficient time and assimilates for grain filling are provided. Therefore, it is quite feasible to improve rice yield by increasing the number of spikelets and expanding the size of the sink, and LA is one possible approach.

\section{The differentiation and degradation of spikelets}

In rice production, the efficient use of nitrogen fertilizers is a critical factor in achieving a high, stable yield (Hirel and Lemaire, 2005; Tylaran et al., 2009). Many studies have been carried out to increase the number of spikelets per panicle using different nitrogen applications to increase crop production and ensure a good harvest. In our study, the PDeS under the different treatments was in the range of $4 \%$ to $6 \%$ (Table 3). The NSS, NDeS, NDiS, and PDeS among the different cultivars was Fyou498 > IIyou498 > Chuanxiang9838. However, the differences were not significant. The NSS in the different treatments of the cultivars followed a ranking (LA $>$ TA) that was similar to that of the NDiS. The NSS and NDiS in LA was significantly higher than that resulting from TA, especially for the Fyou498 cultivar, which increased by $15 \%$ (NSS) and $14 \%$ (NDiS). This result proved that LA can effectively increase NSS, which is similar to the results reported by Kamiji et al. (2011). In contrast, the NDeS and PDeS of the different treatments among the cultivars were inconsistent, but little difference was found. The NSS is primarily determined by NDiS and secondarily by NDeS. This result indicates that the increase in NDiS rather than the decrease in NDeS led to the increased NSS under LA. The effect of the nitrogen applications on NSS, NDeS, and NDiS at various primary branch sites (Figure 2) also showed that the entire set of distribution characteristics of NSS was the same as that of NDiS. Compared with TA, LA resulted in an increase in NDiS on almost all of the primary branches, and the difference was significant for the $2^{\text {nd }}$, $6^{\text {th }}$, and $8^{\text {th }}$ to $10^{\text {th }}$ sites of the primary branches. This pattern provided further evidence that the increased NDiS was the reason that LA increased NSS. In addition, although NSS and NDeS were positively correlated with NDiS, the slope and correlation coefficient between NSS and NDiS were higher than those between NDeS and NDiS (Table 4). Therefore, increasing NDiS is an effective way to increase NSS.

It is worth noting that although the different nitrogen applications and cultivars did not differ with respect to NDeS, the degradation sites of the spikelets on the primary and secondary branches showed obvi-

Table 2 - Effects of $\mathrm{N}$ applications on rice yield and its components.

\begin{tabular}{lccccc}
\hline Parameter & Panicles & No. of grains per panicle & Setting percentage & 1000-grain weight & Yield \\
\hline Fyou498 & $\times 10^{4} \mathrm{ha}^{-1}$ & & $\%$ & $\mathrm{~g}$ & $\mathrm{~kg} \mathrm{ha}^{-1}$ \\
Ilyou498 & $190.8 \pm 7.77$ & $189.8 \pm 16.78$ & $88.8 \pm 4.00$ & $30.2 \pm 0.95$ & $9225.6 \pm 479.60$ \\
Chuanxiang9838 & $190.3 \pm 10.20$ & $166.3 \pm 8.65$ & $94.4 \pm 1.85$ & $30.7 \pm 0.49$ & $9233.6 \pm 301.66$ \\
TA & $216.1 \pm 9.21$ & $150.6 \pm 11.90$ & $87.9 \pm 2.14$ & $29.9 \pm 0.55$ & $9408.7 \pm 341.44$ \\
LA & $197.2 \pm 10.63$ & $159.0 \pm 14.79$ & $90.9 \pm 3.56$ & $30.5 \pm 0.58$ & $9011.1 \pm 406.88$ \\
Cultivar (C) & $200.9 \pm 12.20$ & $178.8 \pm 14.75$ & $89.8 \pm 2.89$ & $30.1 \pm 0.80$ & $9567.6 \pm 260.78$ \\
N application (N) & $20.0^{* *}$ & $21.8^{* *}$ & $20.4^{* *}$ & $1.2^{\text {NS }}$ & $0.3^{\text {NS }}$ \\
C $\times$ N & $0.9^{\text {NS }}$ & $16.4^{* *}$ & $2.5^{\text {NS }}$ & $1.2^{\text {NS }}$ & $6.6^{*}$ \\
TA & $1.8^{\text {NS }}$ & $1.0^{\text {NS }}$ & $1.6^{\text {NS }}$ & $1.0^{\text {NS }}$ & $0.2^{\text {NS }}$ \\
\hline
\end{tabular}

$\mathrm{TA}=$ traditional $\mathrm{N}$ fertilization method; $\mathrm{LA}=$ late $\mathrm{N}$ application; * and ** indicate significance at the 0.05 and 0.01 probability levels, respectively, and NS indicates not significant at $p<0.05$. Table values represent the mean \pm standard deviation. 
Table 3 - The influence of $\mathrm{N}$ application on spikelet differentiation and degradation.

\begin{tabular}{|c|c|c|c|c|c|}
\hline Cultivar & $\mathrm{N}$ application & NSS & NDeS & NDiS & PDeS \\
\hline & & & - per panicle - & 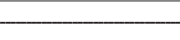 & $\%$ \\
\hline \multirow{2}{*}{ Fyou498 } & TA & $190.7 \pm 1.50$ & $12.9 \pm 3.53$ & $203.6 \pm 4.56$ & $6.1 \pm 1.59$ \\
\hline & LA & $219.2 \pm 8.21$ & $12.8 \pm 3.07$ & $232.0 \pm 9.71$ & $5.3 \pm 1.23$ \\
\hline \multirow{2}{*}{ Ilyou498 } & TA & $191.0 \pm 7.94$ & $9.4 \pm 1.10$ & $200.4 \pm 8.97$ & $4.6 \pm 0.37$ \\
\hline & LA & $201.5 \pm 9.52$ & $10.5 \pm 2.23$ & $211.9 \pm 11.74$ & $4.8 \pm 0.74$ \\
\hline Chuanxiang & TA & $186.9 \pm 2.61$ & $7.2 \pm 1.27$ & $194.1 \pm 3.46$ & $3.6 \pm 0.60$ \\
\hline \multirow[t]{2}{*}{9838} & LA & $194.4 \pm 1.19$ & $7.8 \pm 0.44$ & $202.2 \pm 0.99$ & $3.8 \pm 0.22$ \\
\hline & Fyou498 & $204.9 \pm 7.39$ & $12.9 \pm 2.09$ & $217.8 \pm 7.97$ & $5.7 \pm 1.17$ \\
\hline \multirow[t]{2}{*}{ Cultivar } & Ilyou498 & $196.2 \pm 6.02$ & $9.9 \pm 1.14$ & $206.1 \pm 7.10$ & $4.7 \pm 0.49$ \\
\hline & Chuanxiang9838 & $190.7 \pm 2.11$ & $7.5 \pm 0.62$ & $198.1 \pm 2.42$ & $3.7 \pm 0.43$ \\
\hline \multirow{3}{*}{$\mathrm{N}$ application } & $\mathrm{TA}$ & $189.5 \pm 2.54$ & $9.8 \pm 1.40$ & $199.3 \pm 3.37$ & $4.7 \pm 0.79$ \\
\hline & LA & $205.0 \pm 5.18$ & $10.3 \pm 1.32$ & $215.4 \pm 6.12$ & $4.6 \pm 0.64$ \\
\hline & Cultivar (C) & $3.0^{\mathrm{NS}}$ & $2.8^{\mathrm{NS}}$ & $3.5^{\mathrm{NS}}$ & $2.4^{\text {NS }}$ \\
\hline \multirow[t]{2}{*}{$\mathrm{F}$ value } & $\mathrm{N}$ application (N) & $10.4^{* *}$ & $0.1^{\mathrm{NS}}$ & $7.0^{*}$ & $0.1^{\mathrm{NS}}$ \\
\hline & $\mathrm{C} \times \mathrm{N}$ & $1.9^{\mathrm{NS}}$ & $0.1^{\mathrm{NS}}$ & $1.1^{\mathrm{NS}}$ & $0.2^{\mathrm{NS}}$ \\
\hline
\end{tabular}

TA = traditional N fertilization method; LA = late N application; NSS = number of surviving spikelets; NDeS = number of degenerated spikelets; NDiS = number of differentiated spikelets; PDeS $=$ percentage of degenerated spikelets. Table values represent the mean \pm standard error; * and * ${ }^{*}$ indicate significance at the 0.05 and 0.01 probability levels, respectively, and NS indicates not significant at $p<0.05$.

Table 4 - The correlation analysis between number of spikelets and number of secondary branches.

\begin{tabular}{|c|c|c|c|c|c|c|}
\hline & \multicolumn{3}{|c|}{ NSS } & \multicolumn{3}{|c|}{ NDeS } \\
\hline & a & $b$ & $r$ & $a$ & $b$ & $r$ \\
\hline NSS & - & - & - & 0.1457 & -18.671 & $0.52^{*}$ \\
\hline NDeS & 1.8852 & 178.27 & $0.52^{*}$ & - & - & - \\
\hline NDiS & 0.8371 & 23.708 & $0.98^{* *}$ & 0.1629 & -23.708 & 0.69 ** \\
\hline PDeS & 3.0977 & 182.42 & 0.35 & 2.3902 & -1.3803 & $0.98^{* *}$ \\
\hline NSSB & 3.8093 & 14.178 & $0.96^{* *}$ & 0.7339 & -25.199 & $0.66^{* *}$ \\
\hline NDeSB & -1.8403 & 236.37 & -0.41 & -0.2931 & 16.304 & -0.24 \\
\hline NDiSB & 2.351 & 34.269 & $0.59^{* *}$ & 0.5019 & -24.713 & 0.45 \\
\hline PDeSB & -2.329 & 268.6 & $-0.67^{* \text { * }}$ & -0.4125 & 22.712 & -0.43 \\
\hline NSPB & -9.5584 & 316.25 & -0.19 & -2.764 & 44.483 & -0.2 \\
\hline
\end{tabular}

NSS = number of surviving spikelets; NDeS = number of degenerated spikelets; NDiS = number of differentiated spikelets; PDeS = percentage of degenerated spikelets; NSSB = number of surviving secondary branches; $\mathrm{NDeSB}=$ number of degenerated secondary branches; NDiSB = number of differentiated secondary branches; PDeSB = percentage of degenerated secondary branches; NSPB = number of surviving primary branches; * and ** indicate significance at the 0.05 and 0.01 probability levels, respectively; The lowercase letters "a," "b" and "r" represent the slope, nodal increment and correlation coefficient, respectively.

ous differences. The degradation rate of each site of the primary spikelets (located directly on the primary branches) increased from the base to the apex (Figure 3). In addition, the percentage of degenerated apical terminal spikelets was considerably larger than that of the basal lateral spikelets, whereas the degradation of the secondary spikelets (located on secondary branches) exhibited the opposite result, i.e., there was a higher degree of degradation on the basal lateral spikelets. Ko and Junko (2002) reported that the initiation of the terminal and lateral spikelets was controlled by different genetic programs. This study also indicated that there is great
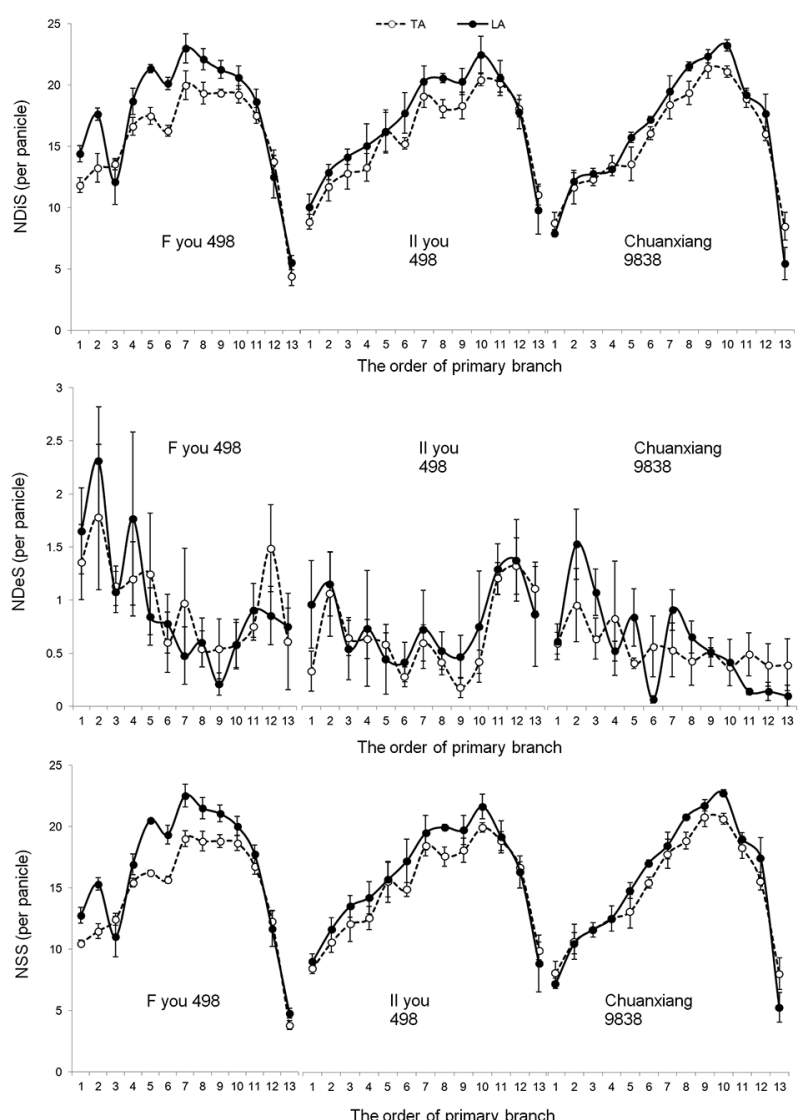

Figure 2 - The distribution characteristics of spikelets on different primary branches. $\mathrm{TA}=$ traditional $\mathrm{N}$ fertilization method; $\mathrm{LA}=$ late $\mathrm{N}$ application; NSS = number of surviving spikelets; NDeS = number of degenerated spikelets; NDiS = number of differentiated spikelets. 
variation in the spatial expression of related genes that function to control the degradation of basal lateral and apical terminal spikelets. Spikelet degradation occurred mainly at the panicle apex and base; therefore, a full understanding of the influencing factors and regulatory mechanisms of basal lateral and apical terminal spikelets will help to reduce spikelet degradation and increase rice yield.

Kamiji et al. (2011) noted that the time effect of topdressing on spikelet number was generally greatest when nitrogen fertilizer was top-dressed between 30 and 35 days before heading. According to the growth and development regulation of indica hybrid rice, 30 to 35 days before heading coincides with the jointing stage. Therefore, a higher amount of nitrogen accumulation, resulting from LA, could provide more nutrients for spikelet

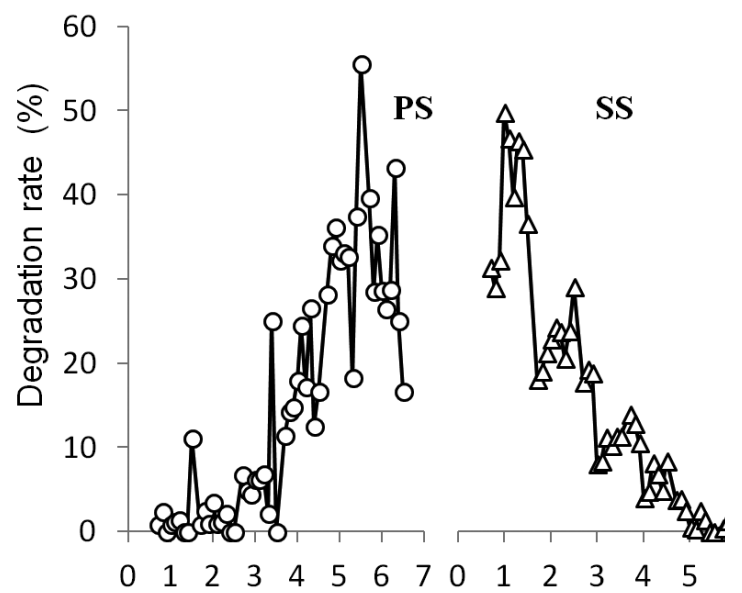

Figure 3 - The distribution characteristics of the spikelet degradation sites. $\mathrm{PS}=$ primary spikelet; $\mathrm{SS}=$ secondary spikelet. differentiation. Ding and Maruyama (2004) reported that a japonica rice cultivar (Nipponbare) with topdressing (7 days before panicle initiation) and an indica rice cultivar (Takanari) without topdressing had 1.8 and 2.7 times more spikelets per panicle, respectively, compared with Nipponbare without topdressing. These findings, along with the results of the present study, indicate that because of the large sink size of indica rice cultivars, the effect of nitrogen topdressing applied at the panicle initiation stage on spikelets per panicle was greater in japonica than in indica rice cultivars. However, whether japonica or indica rice cultivars are used, the application of nitrogen fertilizer at the panicle initiation stage is an effective technical measure to increase the number of spikelets to achieve the goal of yield improvement.

\section{The differentiation and degradation of branches}

A rice panicle consists of a number of primary branches, secondary branches and spikelets, and the spikelets are attached to primary branches and secondary branches. Therefore, the NSSB and NSPB must change under different nitrogen application regimes because of the significant difference in NSS. The data presented in Table 5 show a large varietal variation in NDeSB, NSPB, and PDeSB. The PDeSB of the IIyou498 cultivar was the highest among the cultivars, and NSPB was also the highest and was significantly different from the other cultivars studied. Compared with the IIyou498 cultivar, PDePB and NSPB of the Fyou498 cultivar were lower, but NSSB of the Fyou498 cultivar was the highest. The PDeSB of the Fyou498 cultivar was significantly lower than that of the IIyou498 and Chuanxiang9838 cultivars, which indicated that NSPB is not the only factor that determines the NSSB. The PDePB for all of the treatments was below $1 \%$, and PDePB under TA was significantly higher than that resulting from LA.

Table 5 - The influence of $\mathrm{N}$ application on branch differentiation and degradation.

\begin{tabular}{|c|c|c|c|c|c|c|c|}
\hline Cultivar & $\mathrm{N}$ application & NSSB & NDeSB & NDiSB & PDeSB & NSPB & PDePB \\
\hline & & & - per panicle - & 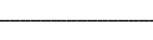 & $\%$ & per panicle & $\%$ \\
\hline \multirow{2}{*}{ Fyou498 } & TA & $47.0 \pm 1.05$ & $20.5 \pm 0.81$ & $67.4 \pm 0.68$ & $30.3 \pm 1.22$ & $12.2 \pm 0.05$ & $0.0 \pm 0.0$ \\
\hline & LA & $53.4 \pm 1.67$ & $16.6 \pm 0.68$ & $70.0 \pm 1.69$ & $23.7 \pm 1.01$ & $12.2 \pm 0.11$ & $0.0 \pm 0.0$ \\
\hline \multirow{2}{*}{ Ilyou498 } & TA & $46.1 \pm 2.43$ & $25.7 \pm 0.17$ & $71.5 \pm 2.10$ & $36.0 \pm 1.11$ & $12.9 \pm 0.13$ & $0.5 \pm 0.28$ \\
\hline & LA & $49.0 \pm 2.56$ & $22.6 \pm 0.87$ & $71.6 \pm 3.27$ & $31.6 \pm 0.75$ & $12.7 \pm 0.08$ & $0.0 \pm 0.0$ \\
\hline Chuanxiang & TA & $45.9 \pm 1.02$ & $20.5 \pm 1.79$ & $66.4 \pm 2.45$ & $30.7 \pm 1.74$ & $12.5 \pm 0.02$ & $0.9 \pm 0.52$ \\
\hline \multirow[t]{2}{*}{9838} & LA & $47.4 \pm 0.41$ & $21.6 \pm 1.37$ & $69.0 \pm 1.01$ & $31.3 \pm 1.55$ & $12.3 \pm 0.06$ & $0.0 \pm 0.0$ \\
\hline & Fyou498 & $50.2 \pm 1.69$ & $18.5 \pm 0.98$ & $68.7 \pm 1.0$ & $27.0 \pm 1.06$ & $12.2 \pm 0.06$ & $0.0 \pm 0.0$ \\
\hline \multirow[t]{2}{*}{ Cultivar } & Ilyou498 & $47.6 \pm 1.70$ & $24.1 \pm 0.80$ & $71.5 \pm 1.74$ & $33.8 \pm 0.70$ & $12.8 \pm 0.08$ & $0.3 \pm 0.25$ \\
\hline & Chuanxiang9838 & $46.6 \pm 0.59$ & $21.1 \pm 1.04$ & $67.7 \pm 1.32$ & $31.0 \pm 0.65$ & $12.4 \pm 0.07$ & $0.4 \pm 0.43$ \\
\hline \multirow{3}{*}{$\mathrm{N}$ application } & TA & $46.3 \pm 0.84$ & $22.2 \pm 1.04$ & $68.4 \pm 1.23$ & $32.3 \pm 0.70$ & $12.5 \pm 0.11$ & $0.5 \pm 0.36$ \\
\hline & LA & $50.0 \pm 1.27$ & $20.3 \pm 1.06$ & $70.2 \pm 1.16$ & $28.8 \pm 0.90$ & $12.4 \pm 0.08$ & $0.0 \pm 0.0$ \\
\hline & Cultivar (C) & $2.4^{\mathrm{NS}}$ & $14.2^{* *}$ & $2.5^{\mathrm{NS}}$ & $12.4^{* *}$ & $25.3^{* *}$ & $1.7^{\mathrm{NS}}$ \\
\hline \multirow[t]{2}{*}{ F value } & $\mathrm{N}$ application (N) & $6.9^{*}$ & $5.0^{*}$ & $1.5^{\mathrm{NS}}$ & $9.8^{*}$ & $5.5^{*}$ & $6.5^{*}$ \\
\hline & $\mathrm{C} \times \mathrm{N}$ & $1.2^{\mathrm{NS}}$ & $3.2^{\mathrm{NS}}$ & $0.3^{\mathrm{NS}}$ & $3.4^{\mathrm{NS}}$ & $1.2^{\mathrm{NS}}$ & $1.7^{\mathrm{NS}}$ \\
\hline
\end{tabular}

$\mathrm{TA}=$ traditional $\mathrm{N}$ fertilization method; $\mathrm{LA}=$ late $\mathrm{N}$ application; NSSB = number of surviving secondary branches; NDeSB = number of degenerated secondary branches; NDiSB = number of differentiated secondary branches; PDeSB = percentage of degenerated secondary branches; NSPB = number of surviving primary branches; PDePB = percentage of degenerated primary branches; Table values represent the mean \pm standard error; * and ** indicate significance at the 0.05 and 0.01 probability levels, respectively, and NS indicates not significant at $p<0.05$. 
The nitrogen applications did not differ significantly with respect to the number of differentiated secondary branches (NDiSB), whereas compared with TA, the NDeSB and the PDeSB under LA were reduced by $9 \%$ and $11 \%$, respectively; these differences were significant. Therefore, LA significantly increased NSSB by 8 $\%$ because of the decrease in NDeSB and PDeSB, rather than the increase in NDiSB. The effects of the nitrogen applications on NDeSB, PDeSB, and NDiSB at different primary branch sites (Figure 4) also showed that little significant difference existed in NDiSB of the different nitrogen treatments. In addition, compared with TA, LA decreased NDeSB of the Fyou 498 and IIyou498 cultivars at almost all of the primary branch sites. With respect to the three cultivars, the NDeSB under LA was significantly less than that of TA for the $6^{\text {th }}, 9^{\text {th }}$, and $10^{\text {th }}$ sites of the primary branches. Therefore, there was no doubt that the decrease in NDeSB was the main reason for the increase in NSSB.

Previously reported genes, such as MONOCULM1 (MOCl) and Short Panicle1 (SP1), were recently

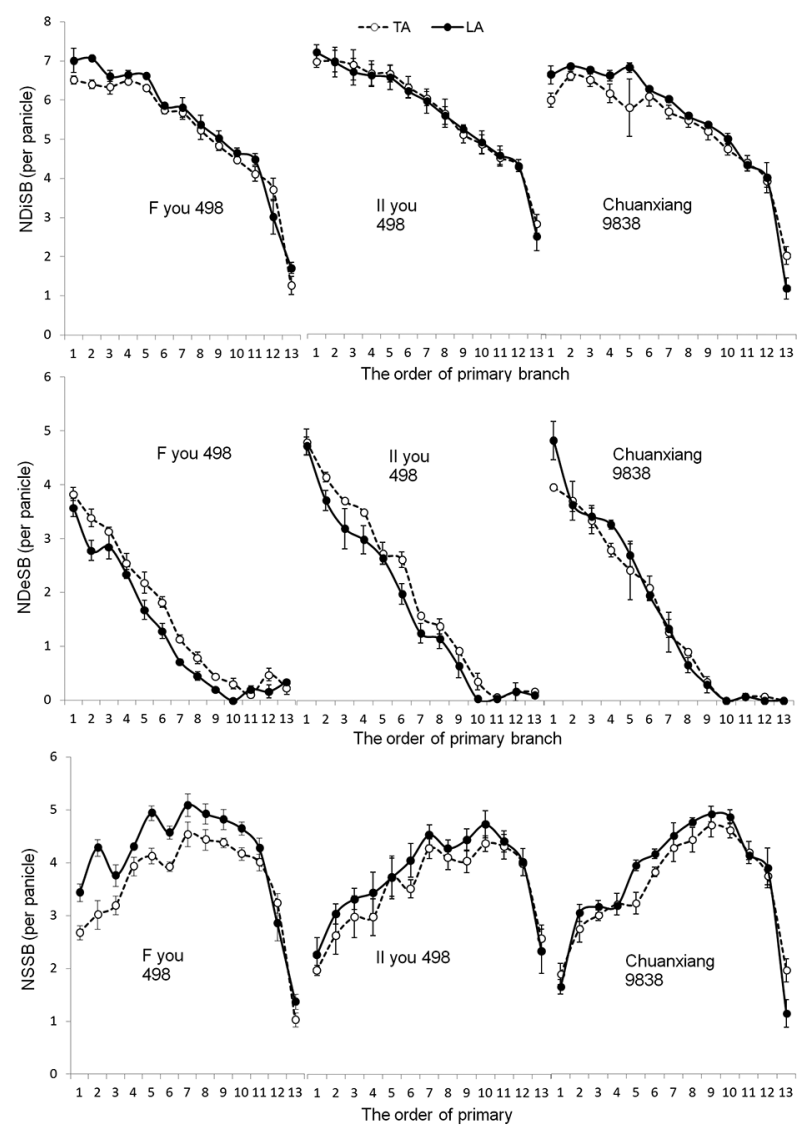

Figure 4 - The distribution characteristics of secondary branches on different primary branches. $\mathrm{TA}=$ traditional $\mathrm{N}$ fertilization method; $\mathrm{LA}=$ late $\mathrm{N}$ application; NSSB = number of surviving secondary branches; NDeSB = number of degenerated secondary branches; NDiSB $=$ number of differentiated secondary branches. characterized as key factors that regulate the development of rice panicle branches (Li et al., 2003). MOC1 plays important roles in axillary meristem initiation in rice, and SP1 encodes a putative transporter that belongs to the peptide transporter family and determines rice panicle size (Li et al., 2009). According to our study, different treatments did not lead to significant differences in NDiSB, indicating that there was no substantial treatment influence on the expression of the genes (i.e., MOC1) that encode axillary meristem initiation in panicles. However, LA changed the nitrogen supply level at the panicle initiation stage, which may influence the expression of SP1, thereby affecting the NSS. Wang and Li (2011) noted that the identification of the transported substrate of SP1 helps to establish the link between the development of panicle branches and the utilization of nutrients. It has been well demonstrated that LA can improve rice yield and increase nitrogen use efficiency (Ding and Maruyama, 2004; Peng et al., 2006), but the specific molecular mechanism remains unclear. However, SP1 appears to be an important factor.

The degradation of rice branches and spikelets, which is a universal phenomenon in agricultural production, can impact crop yield. The growth and development of spikelets is a complex process that is controlled by many genes, affected by cultivation conditions, and restricted by ecological factors. It is difficult to control the ecological environment; therefore, cultivation and management techniques are key to improving yield potential. From the perspective of obtaining the maximum potential yield described by Sheehy et al. (2001), we know that decreasing spikelet degeneration is the first step to improving crop yield. However, the number of rice panicle branches determines the number of spikelets; therefore, it is important to increase NSSB. The results showed that NSSB was significantly and positively correlated with NSS $(r=0.96, p=0.01$; Table 4). Therefore, the key to increasing the NSS is to increase the NSSB, which can be achieved by regulating the expression of related genes, such as MOC1, and providing adequate nutrition through LA. Moreover, PDeSB was as high as $31 \%$, which indicates that the yield of indica hybrid rice has considerable potential for improvement.

\section{Conclusions}

The number of spikelets per panicle is one of the most important components of rice yield, and this component was significantly influenced by nitrogen fertilizer applications. The results showed that the number of grains per panicle under LA was $12 \%$ higher than that under TA, which was the main reason for yield improvement. In addition, LA increased the grain number due to the increase in NSS, which resulted from an increase in NDiS and a decrease in NDeSB. Furthermore, the PDeSB was as high as $31 \%$, which indicates that the yield of indica hybrid rice has considerable potential for improvement. Therefore, a full understanding of the in- 
fluencing factors and regulatory mechanisms involved in NDiS and NSSB will help to increase NSS and ultimately lead to a higher yield. Late nitrogen application is highly effective in enhancing the spikelet number of indica hybrid rice, and its mechanism is worthy of further study and exploitation.

\section{References}

Angus, J.F.; Bowden, J.W.; Keating, B.A. 1993. Modeling nutrient responses in the field. Plant Soil 156: 57-66.

Bueno, C.S.; Ladha, J.K. 2009. Comparison of soil properties between continuously cultivated and adjacent uncultivated soils in rice-based systems. Biology and Fertility of Soils 45: 499-509.

Demotes, M.S.; Jeuffroy, M.H. 2001. Incorporating radiation and nitrogen nutrition into a model of kernel number in wheat. Crop Science 41: 415-423.

Ding, Y.F.; Maruyama, S. 2004. Proteins and carbohydrates in developing rice panicles with different numbers of spikelets. Plant Production Science 7: 16-21.

Gathala, M.K.; Ladha, J.K.; Saharawat, Y.S.; Kumar, V.; Sharma, P.K. 2011. Effect of tillage and crop establishment methods on physical properties of a medium-textured soil under a sevenyear rice-wheat rotation. Soil Science Society of America Journal 75: 1851-1862.

Hirel, B.; Lemaire, G. 2005. From agronomy and ecophysiology to molecular genetics for improving nitrogen use efficiency in crops. Journal of Crop Improvement 15: 213-257.

Kamiji, Y.; Yoshida, H.; Palta, J.A.; Sakuratani, T.; Shiraiwa, T. 2011. N applications that increase plant $\mathrm{N}$ during panicle development are highly effective in increasing spikelet number in rice. Field Crops Research 122: 242-247.

Kato, Y.; Kamoshita, A.; Yamagishi, J. 2008. Preflowering abortion reduces spikelet number in upland rice (Oryza sativa L.) under water stress. Crop Science 48: 2389-2395.

Ko, S.; Junko, K. 2002. Rice as a model for comparative genomics of plants. Annual Review of Plant Biology 53: 399-419.

Li, S.B.; Qian, Q.; Fu, Z.M.; Zeng, D.L.; Meng, X.B.; Kyozuka, J.; Maekawa, M.; Zhu, X.D.; Zhang, J.; Li, J.Y.; Wang, Y.H. 2009. Short panicle1encodes a putative PTR family transporter and determines rice panicle size. The Plant Journal 58: 592-605.

Li, X.Y.; Qian, Q.; Fu, Z.M.; Wang, Y.H.; Xiong, G.S.; Zeng, D.L.; Wang, X.; Liu, X.; Teng, S.; Hiroshi, F.; Yuan, M.; Luo, D.; Han, B.; Li, J. 2003. Control of tillering in rice. Nature 422: 618-621.
Liu, G.L.; Mei, H.W.; Zou, G.H.; Liu, H.Y.; Hu, S.P.; Li, M.S.; Wu, J.H.; Chen, L.; Luo, L.J. 2008a. QTL analysis of panicle neck diameter, a trait highly correlated with panicle size, under well watered and drought conditions in rice. Plant Science 174: 71-77.

Liu, H.J.; Yand, L.X.; Huang, J.Y.; Dong, G.C.; Zhu, J.G.; Liu, G.; Wang, Y.L. 2008b. Effect of free-air $\mathrm{CO}_{2}$ enrichment (FACE) on nitrogen uptake and utilization of three-line indica hybrid rice cultivar Shanyou 63. Journal of Agro-Environment Science 27: 1015-1021.

Matsui, T.; Kagata, H. 2002. Correlation of nitrogen concentration with dry-matter portioning to spikelets and total husk volume on the panicle in japonica rice. Plant Production Science 5: 198202.

Peng, S.B.; Buresh, R.J.; Huang, J.L. 2006. Strategies for overcoming low agronomic nitrogen use efficiency in irrigated rice systems in China. Field Crops Research 96: 37-47.

Qin, J.Q.; Impa, S.M.; Tang, Q.Y.; Yang, S.H.; Yang, J.; Tao, Y.S.; Jagadish, K.S.V. 2013. Integrated nutrient, water and other agronomic options to enhance rice grain yield and $\mathrm{N}$ use efficiency in double-season rice crop. Field Crops Research 148: $15-23$.

Sheehy, J.E.; Dionora, M.J.A.; Mitchell, P.L. 2001. Spikelet numbers, sink size and potential yield in rice. Field Crops Research 71: 77-85.

Shiratsuchi, H.; Ohdaira, Y.; Takanashi, J. 2007. Relationship between dry weight at heading and the number of spikelets on individual rice tillers. Plant Production Science 10: 430-441.

Tylaran, R.D.; Ozawa, S.; Miyamoto, N.; Ookawa, T.; Motobayashi, T.; Hirasawa, T. 2009. Performance of a high-yielding modern rice cultivar Takanari and several old and new cultivars grown with and without chemical fertilizer in a submerged paddy field. Plant Production Science 12: 365-380.

Wang, Y.H.; Li, J.Y. 2011. Branching in rice. Current Opinion in Plant Biology 14: 94-99.

Yao, Y.; Yamamoto, Y.; Yoshida, T.; Nitta, Y.; Miyazaki, A. 2000. Response of differentiated and degenerated spikelets to topdressing, shading and day/night temperature treatments in rice cultivars with large panicles. Soil Science and Plant Nutrition 46: 631-641.

Zhang, Q. 2007. Strategies for developing green super rice. Proceedings of the National Academy of Sciences of the United States of America 104: 16402-16409. 